\title{
Ameboma versus colorectal cancer: a case report
}

\author{
Uccelli F $F^{1}$, Intelisano $A^{1}$, Piccinali $D^{1}$, Zanello $A^{2}$, Meroni $R^{2}$, Pedone $L^{2}$, Gaffuri $\mathrm{N}^{3}$ and Goletti $\mathrm{O}^{1}$ \\ ${ }^{1}$ General Surgery Unit, Humanitas Gavazzeni, Bergamo, Italy \\ ${ }^{2}$ Department of Radiology, Humanitas Gavazzeni, Bergamo, Italy \\ ${ }^{3}$ Digestive Endoscopy Unit, Humanitas Gavazzeni, Bergamo, Italy
}

\begin{abstract}
Amoebiasis is a very common disease in tropical countries and represents the second cause of death from parasitic disease in the world but in Western Europe and in United States is very uncommon. A common symptom is colitis and a rare complication is ameboma. This complication occurs as a mass of granulation tissue and it mimic colorectal cancer.
\end{abstract}

It is important to make a correct differential diagnosis whenever there is a case of abdominal pain and/or diarrhoea in patients who have been to countries where Entamoeba is endemic.

Amoebiasis is a very common disease in tropical countries and represents the second cause of death from parasitic disease in the world [1] but in Western Europe and in United States is very uncommon [2].

Nevertheless, cases of amebiasis may occur also in these countries, so it is important to make a correct differential diagnosis whenever there is a case of abdominal pain and/or diarrhoea in patients who have been to countries where Entamoeba is endemic.

We describe a case of intestinal amoebiasis in a young Italian man.

A.M. is a 52-year-old man who works as cook in Guinea for about five months. He has come back in Italy to carry out a medical examination for persistent diarrhoea. At the medical visit the patient appeared in poor general conditions, with diffused abdominal pain. He referred bloody diarrhoea for about fifteen days. An abdominal ultrasound was performed showing a mass in the right colon. A rectal exploration showed another mass at the rectum.

Considering the clinical pattern and the suspicion of a multifocal tumour, the patient was hospitalized. Hematic examinations found only a modest electrolyte imbalance and a slight alteration in liver function.

A CT scan was performed showing thickening of the right colon walls from the hepatic flexure to the cecum (Figure 1), associated with the presence of multiple lymph nodes in the perivisceral fat tissue, with a maximum diameter of about $18 \mathrm{~mm}$. Even the walls of the terminal ileus appeared thickened and oedematous. Furthermore, the distal rectus and sigma appeared thicker with associated multiple enlarged lymph nodes, with a maximum diameter of about $8-9 \mathrm{~mm}$. In the rectum there was a luminal tissue vegetation (Figure 2).

The patient was then subjected to colonoscopy that showed extensive ulcerated areas with mild tissue necrosis and oedema of the intestinal mucosa from rectum to sigma (Figure 3). Multiple biopsies were performed on the rectum and the sigma. The pathologic report described the presence of microorganisms morphologically related to Entamoeba Histolytica (Figure 4), in the context of active chronic, ulcerative colitis (Figure 5). Intravenous antibiotic therapy with Piperacillin/Tazobactam, Amikacin and Metronidazole was started.

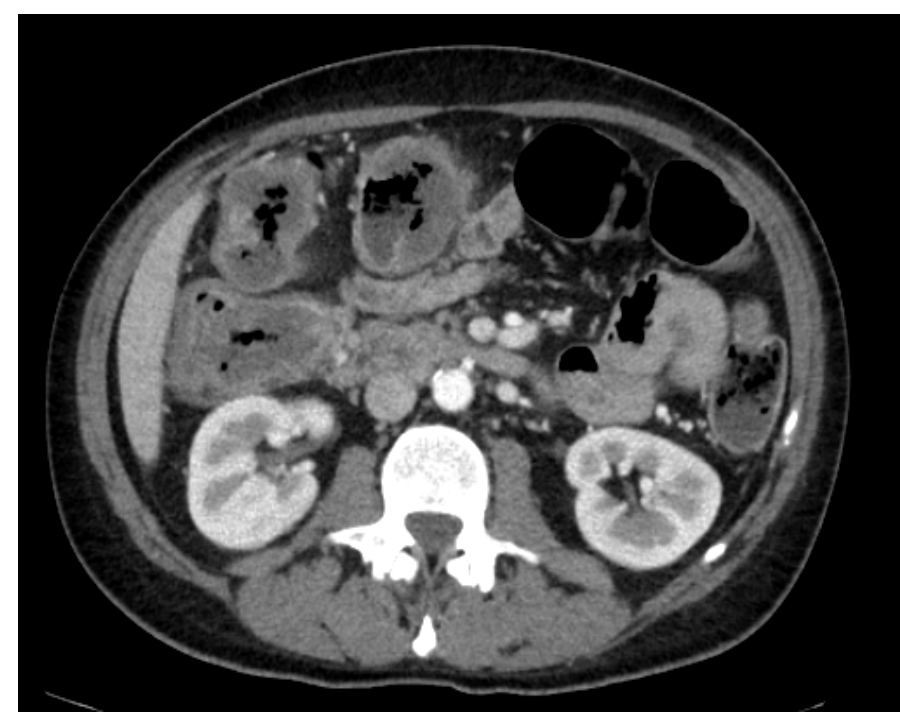

Figure 1. CT scan image of the right colon walls thickening

In a few days, the patient has a progressive improvement in the clinical conditions. A CT scan was then performed with reduction of lymphadenopathy and an initial reduction in the thickness of the colon wall (Figure 6).

Eight days after hospitalization, the patient was discharged and continued antibiotic therapy at home under close medical monitoring.

*Correspondence to: Fara Uccelli, General Surgery Unit, Humanitas Gavazzeni, Bergamo, Italy, Tel: +390354204548; Fax: +390354204744; E-mail: fara.uccelli@gavazzeni.it

Key words: Amoeba, Amoebiasis, Ameboma, Colorectal cancer

Received: March 05, 2018; Accepted: March 22, 2018; Published: March 26, 2018 
After one week, the patient performed an abdomen ultrasound that showed a further progressive regression in bowel thickening. Patient was asymptomatic, control blood tests were normal.

Amoebiasis is caused by a protozoan parasite called Entamoeba Histolytica.

The human and some primates are the only natural hosts of this amoeba. The transmission is orofecal, by ingestion of cysts present in food or water contaminated with faeces of infected subjects or, more rarely, by oral or anal sex.

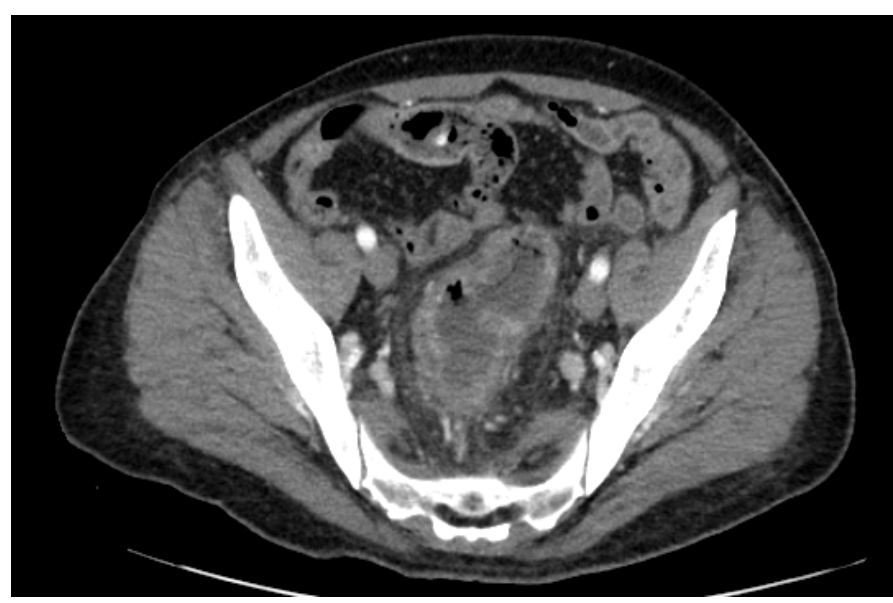

Figure 2. CT scan image of the thickening with luminal vegetation of the rectum
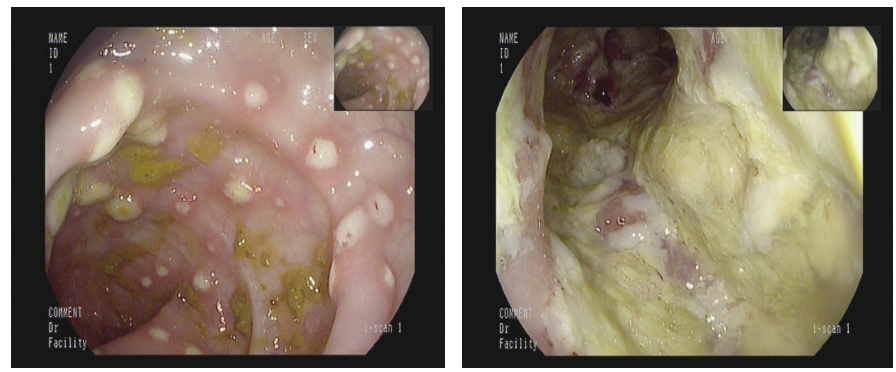

Figure 3. Endoscopic image of intraluminal granulation tissue of colon and rectum

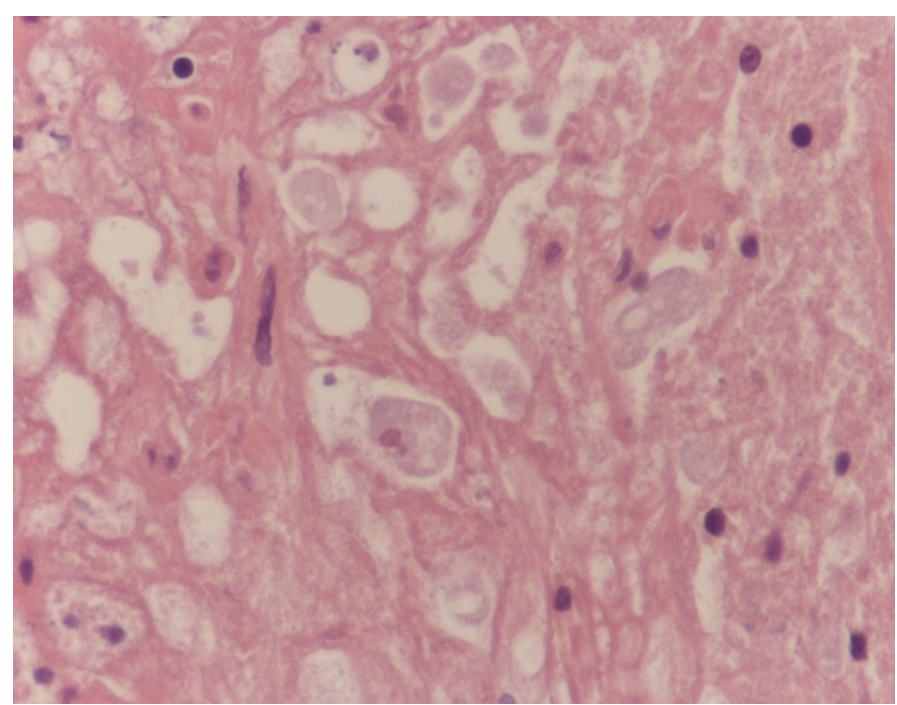

Figure 4. Entamoeba Histolytica in histological sample

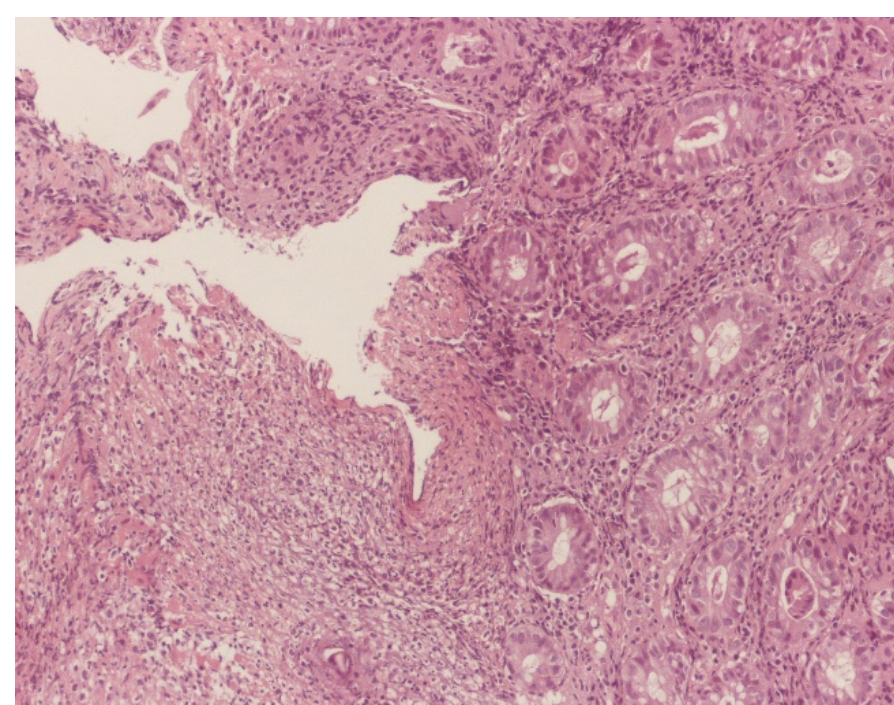

Figure 5. Histological sample of ulcerative colitis

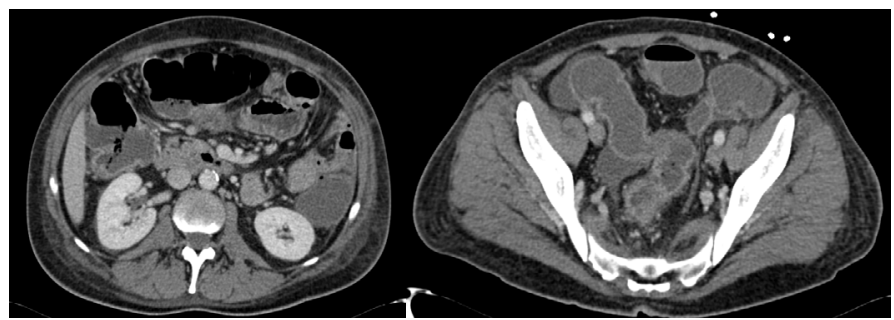

Figure 6. CT scan image after one week of treatment

Entamoeba Histolytica is present all over the world but is more common in countries where there are poor hygienic standards and it is responsible for about 40,000 to 100,000 deaths per year [1].

Our patient lived in Guinea for months, which is a developing country. In addition, his job is related to close contact with local semiprocessed materials used for food production. Hygienic standards are often not guaranteed. For these reasons this patient was at risk of colonization by Entamoeba Histolytica.

Most people with Entamoeba Histolytica are asymptomatic and only $4-10 \%$ of these will develop symptoms in subsequent years $[3,4]$.

When the infection becomes symptomatic, it can affect several body regions; the most common are the gastrointestinal tract, the liver, the respiratory tract, the brain, but there are cases of amoebiasis of urinary tract, genitalia, perineal region and skin [5-7].

Regarding the bowel, the most common symptom is colitis. Occasionally, amoebic colitis may be fulminant, with acute abdominal pain, fever, leucocytosis, bloody diarrhoea, peritonitis $[8,9]$.

In the large part of cases amoebic colitis onset is gradual and symptoms last for weeks. Mucoid stools and diarrhoea are typical but also rectal bleeding without diarrhoea can be present [10,11]. A rare complication of amoebic colitis is ameboma. This complication occurs as a mass of granulation tissue, usually found in the cecum ad the ascending colon and it is related to amoebic chronic infection. Ameboma may mimic colon carcinoma, Crohn's disease, carcinoma of the colon, non-Hodgkin's lymphoma, tuberculosis, fungal infection, AIDS-associated lymphoma and Kaposi's sarcoma [12]. It can also evolve in perforation, obstruction, intussusception, anorectal fistula and appendicitis $[13,14]$. 
In the described case, the patient reported the beginning of symptoms with bleeding, which he attributed to piles. Subsequently, modest but persistent for week mucosal diarrhoea appeared, associated with asthenia and modest weight loss. Despite the typical symptoms of amoebiasis, these manifestations mimic the typical symptomatology of colorectal tumour. Furthermore, the CT scan showed the amebomas in colon and rectum, that consistent with a neoplasm. Although the clinical history and lifestyle of the patient were highly suggestive to a parasitical disease, it was essential to get a diagnosis to define the therapeutic strategy.

The identification of Entamoeba Histolytica in stools allows the diagnosis. Sometimes Entamoeba Histolytica is not detectable in stools from the very beginning. In these cases a mucosal biopsy made by colonoscopy represents a useful method for the diagnosis $[15,16]$ and allows to make differential diagnosis and to start the appropriate treatment properly.

Metronidazole is considered the drug of choice for the amoebiasis treatment, in association with a luminal-acting cysticidal agent. Therapy must be administered from 5 to 10 days.

As already mentioned, amoebiasis is a very uncommon disease in Europe. Nevertheless, in the last few decades, immigration phenomena and travels from/to developing countries, both for business and tourism, are increasing. These factors can, as in the case described above, lead to improvement of amoebiasis infections observed even outside typical geographic areas.

In addition, intestinal amoebiasis has symptoms and patterns of presentation that can mimic other common pathologies such as neoplasms, but requires timely surgical therapy, especially in cases of perforation or occlusion. Therefore, is important to analyse the patient's history and to obtain a definitive diagnosis before starting any treatment.

\section{Conflict of interest}

All the authors have no conflicts of interest to disclose.

\section{References}

1. Stanley SL (2003) Amoebiasis. Lancet 361: 1025-1034.

2. Spinzi G, Pugliese D, Filippi E (2016) An Unexpected Cause of Chronic Diarrhea. Gastroenterology 150: e5-6. [Crossref]

3. Gathiram V, Jackson TF (1987) A longitudinal study of asymptomatic carriers of pathogenic zymodemes of Entamoeba histolytica. S Afr Med J 72: 669-672. [Crossref]

4. Irusen EM, Jackson TF, Simjee AE (1992) Asymptomatic intestinal colonization by pathogenic Entamoeba histolytica in amebic liver abscess: prevalence, response to therapy, and pathogenic potential. Clin Infect Dis 14: 889-893. [Crossref]

5. Kirsh D, Diaz-Rivera RS (1943) Perinephric abscess-a previously unreported complication of amebiasis. The American Journal of the Medical Sciences 206: $372-$ 378.

6. Heinz KP (1973) Amoebic infection of the female genital tract. A report of three cases. $S$ Afr Med J 47: 1795-1798. [Crossref]

7. Thomas JA, Antony AJ (1976) Amoebiasis of the penis. Br J Urol 48: 269-273. [Crossref]

8. Aristizábal H, Acevedo J, Botero M (1991) Fulminant amebic colitis. World J Surg 15 216-221. [Crossref]

9. Takahashi T, Gamboa-Dominguez A, Gomez-Mendez TJM, Tito JM, Maria RJ, et al (1997) Fulminant amebic colitis. Diseases of the Colon \& Rectum 40: 1362-1367.

10. Adams EB, MacLeod IN (1977) I. Amebic Dysentery and its Complications. Medicine 56: 315-323. [Crossref]

11. Jammal MA, Cox K, Ruebner B (1985) Amebiasis Presenting as Rectal Bleeding Without Diarrhea in Childhood. J Pediatr Gastroenterol Nutr 4: 294-296. [Crossref]

12. Lin CC, Kao KY (2013) Ameboma: a colon carcinoma-like lesion in a colonoscopy finding. Case Rep Gastroenterol 7: 438-441. [Crossref]

13. Haque R, Huston CD, Hughes M, Houpt E, Petri WA Jr (2003) Amebiasis. $N$ Engl J Med 348: 1565-1573. [Crossref]

14. (1946) Pathology of Tropical Disease. Am J Clin Pathol 16: 60-60.

15. González-Ruiz A, Haque R, Aguirre A, Castañón G, Hall A, et al (1994) Value of microscopy in the diagnosis of dysentery associated with invasive Entamoeba histolytica. J Clin Pathol 47: 236-239. [Crossref]

16. Melvin DM (1979) Laboratory diagnosis of amebiasis. Clinical Microbiology Newsletter 1:1-2.

Copyright: (C2018 Uccelli F. This is an open-access article distributed under the terms of the Creative Commons Attribution License, which permits unrestricted use, distribution, and reproduction in any medium, provided the original author and source are credited. 